\title{
Temperature extremes in Europe and wintertime large-scale atmospheric circulation: HadCM3 future scenarios
}

\author{
J. Santos ${ }^{1,2, *}$, J. Corte-Real ${ }^{1,3}$ \\ ${ }^{1}$ Centro de Geofísica, Colégio Luís António Verney, Departamento de Física, R. Romão Ramalho 59, Universidade de Évora, \\ 7000 Évora, Portugal \\ ${ }^{2}$ Universidade de Trás-os-Montes e Alto Douro, Departamento de Física, Quinta dos Prados, Apartado 1013, \\ 5000-911 Vila Real, Portugal \\ ${ }^{3}$ Instituto de Ciência Aplicada e Tecnologia, Universidade de Lisboa, 1749-016 Lisboa, Portugal
}

\begin{abstract}
The occurrence of warm (cold) events in winter has increased (decreased) over large areas of Europe in a recent-past period (1961-1990). These trends follow asymmetrical patterns and are detected in both maximum and minimum temperatures. It is shown that these trends can be partially explained by changes in the strength of wintertime large-scale forcing. The North Atlantic Oscillation (NAO) forcing is by far the leading coupling between the large-scale atmospheric circulation and frequencies of occurrence of temperature extremes. In fact, their occurrence is strongly connected to NAO-driven anomalies in geopotential, vorticity and temperature advections. As the third generation of the Hadley Centre global coupled models (HadCM3) is skilful in reproducing currently observed major couplings, it was used as a tool for assessing how, and to what extent, these couplings are projected to change under human-induced climate change. A strong wintertime warming is projected to occur under the B2 and A2 scenarios from the Special Report on Emission Scenarios (SRES), particularly over northeastern Europe and in the A2 scenario. An overall increase (decrease) in the occurrence of warm (cold) events is also projected to occur in future scenarios, mainly due to the increase in mean temperatures (changes in variance are generally irrelevant). An eastward extension of the southern centre-of-action of the NAO towards the Mediterranean Basin is also projected to occur by the end of this century (2070-2099), yielding significant changes in the local/regional relationships between the occurrence of temperature extremes and this 'modified NAO'. Furthermore, projected changes in the surface large-scale forcing are associated with vertically coherent changes in the Northern Annular Mode in response to human-induced changes in radiative forcing.
\end{abstract}

KEY WORDS: Temperature extremes $\cdot$ Large-scale circulation $\cdot$ Europe $\cdot$ Scenarios $\cdot$ HadCM3

\section{INTRODUCTION}

Temperature extremes are usually very perceptible and can cause severe impacts on a wide range of human activities and natural systems. Their study is thus particularly meaningful when assessing and modelling the impacts of climate change. In addition, alterations in the occurrence of extremes are, in fact, more relevant than changes in means, since natural hazards, such as floods, landslides, droughts, heat waves and cold spells are often associated with high frequencies of occurrence of extreme events. Consequently, when modelling climatic impacts, changes in the frequencies of occurrence of temperature extremes acquire more relevance than changes in mean temperatures.

The repeated occurrence of record-breaking temperatures over the last 3 decades was not entirely independent of the gradual increase in mean air temperatures over Europe (Jones \& Moberg 2003, Thorne et al. 2003, Luterbacher et al. 2004). However, it is strongly 
believed that changes in the variability of temperature distributions might also play a significant role in triggering these extreme events (Schar et al. 2004). The combined effect of these 2 factors can lead to dramatic changes in the frequencies of occurrence of extremes. The 2003 heat wave is a recent example of an outstanding extreme episode (e.g. Beniston 2004, Black et al. 2004, Fink et al. 2004) that also provided evidence of changes in the variability of temperature distributions (Schar et al. 2004).

Temperature extremes have been defined according to a relatively large number of parametric and nonparametric indices, and the corresponding observed trends have been extensively analyzed in previous studies (e.g. Tank \& Konnen 2003). In the present study, however, the forcing of large-scale atmospheric circulation over the occurrence of temperature extremes in Europe is analyzed by isolating the respective modes of coupled variability. These modes disclose the main large-scale mechanisms governing the occurrence of temperature extremes in Europe. Despite the existence of many other important controlling mechanisms - such as local or regional atmospheric processes or processes related to surface fluxes of energy, momentum and mass - this study focuses solely on large-scale forcings.

The North Atlantic Oscillation (NAO), which is characterized by a pressure pattern with one 'centreof-action' (COA) located over the Iceland region and another, of opposite sign, located near the Azores (Hurrell 1996, Hurrell et al. 2001), may play a leading role in the occurrence of temperature extremes in Europe. In fact, the NAO governs anomalies in wintertime temperature across the continent (Trigo et al. 2002). The leading orthogonal mode of the surface air temperature over Europe also reflects the response of the temperature field to NAO forcing (Pozo-Vázquez et al. 2001).

Since large-scale atmospheric variability within the Euro-Atlantic sector is reliably reproduced by the most recent global climate models (Corte-Real et al. 1995a, 1999, Osborn et al. 1999, Collins et al. 2001), they might also be able to reliably reproduce the aforementioned large-scale couplings. If the latter assumption is verified, these models can be used to assess potential changes in the large-scale couplings under a future modified climate. This information can then be used as a guideline for the development of appropriate adaptation and mitigation strategies. Although important levels of uncertainty are still present in numerical experiments on climate extremes, climate models remain the most useful tool in the detection of humaninduced climate change.

The third generation of the Hadley Centre coupled model (HadCM3) has been widely used in the detec- tion of human-induced climate change signals (e.g. Johns et al. 2003, Jones et al. 2003, Thorne et al. 2003, Leckebubusch \& Ulbrich 2004, Schar et al. 2004) and is also employed in the present study. Climate change signals in HadCM3 are based on emission scenarios from the Special Report on Emission Scenarios (SRES; Nakicenovic et al. 2000), prepared for the Third Assessment Report of the Intergovernmental Panel on Climate Change (Houghton et al. 2001). These scenarios correspond to specific emission pathways that are in turn linked to divergent storylines of socio-economic development and environmental sustainability. Carbon dioxide concentrations are expected to be of about 850 parts per million by volume (ppmv) in the A2 SRES scenario and 600 ppmv in the B2 SRES scenario by the year 2100. Thus in the A2 scenario, the carbon dioxide concentration more than doubles against the 1990 concentration $(370 \mathrm{ppmv})$. These 2 scenarios therefore provide a wide range of likely potential changes, with climatic changes under A2 expected to be more pronounced than under B2.

As large-scale atmospheric forcing over the summer temperature in Europe is generally very weak-the NAO and weather systems are much weaker than in winter (Barnston \& Livezey 1987) — the present study focuses only on winter months (December-February; DJF). Section 2 describes data and methodology. Section 3 presents the results in 4 subsections. The observed trends in the indices of extremes are described in the first subsection. The observed and simulated couplings are analyzed in the next 2 subsections, and projected changes in the Northern Annular Mode are discussed in the last subsection. Finally, a summary of the main conclusions is provided in Section 4.

\section{DATA AND METHODS}

\subsection{Climate variables and datasets}

The surface atmospheric flow is monitored by daily mean sea level pressure (MSLP) within a wide EuroAtlantic sector $\left(20\right.$ to $85^{\circ} \mathrm{N}, 60^{\circ} \mathrm{W}$ to $\left.56.25^{\circ} \mathrm{E}\right)$, whereas maximum and minimum temperatures, $2 \mathrm{~m}$ above the ground (herein referred to as Tmax and Tmin), over Europe are defined in the following narrower window: 30 to $75^{\circ} \mathrm{N}, 15^{\circ} \mathrm{W}$ to $41.25^{\circ} \mathrm{E}$. The geopotential heights, eastward and northward wind components and temperatures at 850,500 and $50 \mathrm{hPa}$ are also used. All the previous variables were provided by the National Centers for Environmental Prediction/National Center of Atmospheric Research (NCEP/NCAR) reanalyses project (Kalnay et al. 1996) for the recent-past reference period (1961-1990); this is the standard period for calculating 'climatic normals' and is indeed the recom- 
mended reference period when evaluating climate change (WMO 1996). With the exception of Tmax and Tmin, all other variables are defined in a $2.5^{\circ}$ latitude $\times$ $2.5^{\circ}$ longitude grid. Both near-surface temperatures are defined over a finer-scale T62 Gaussian grid (approximately a $1.9^{\circ}$ latitude $\times 1.875^{\circ}$ longitude grid) .

Although the MSLP fields largely reflect the observed data (showing little dependence on model parameterizations) (Kalnay et al. 1996) and are generally reliable reproductions of the observed fields (Reid et al. 2001), the choice of a trustworthy and appropriate near-surface temperature dataset is more complex. Despite daily station data being a valuable source of information on surface atmospheric conditions, these data are not physically coherent and comprise many types of inhomogeneities, which cannot be alleviated by homogenization techniques (Wijngaard et al. 2003). Furthermore, gridded data must be used rather than station data for an appropriate validation of a numerical model (Corte-Real et al. 1995b, New et al. 2001, Kiktev et al. 2003). Still, the most reliable station-based gridded datasets are not available on a daily scale (e.g. Hulme et al. 1998), hampering the identification of extremes on a daily basis. Although Tmax and Tmin in the NCEP/NCAR reanalyses are significantly dependent on numerical parameterizations (Kalnay et al. 1996), they still remain suitable for the detection of large-scale couplings and for the subsequent validation of HadCM3. This is mainly due to the fact that this study focuses on large-scale patterns rather than on small-scale details.

All HadCM3 data are defined in a $2.5^{\circ}$ latitude $\times$ $3.75^{\circ}$ longitude grid and were extracted within the following periods: 1961-1989 (common period to all scenarios in the perturbed model run) and 2070-2099 (future period). The recent-past period is based on historically recorded emissions and the future period on the B2 and A2 SRES emission scenarios. Lastly, the $\mathrm{NAO}$ is quantified by a 2-station index computed as the difference between the normalized pressures recorded at Gibraltar $\left(36.1^{\circ} \mathrm{N}, 5.4^{\circ} \mathrm{W}\right)$ and in southwest Iceland $\left(64.1^{\circ} \mathrm{N}, 22.9^{\circ} \mathrm{W}\right)$ (Jones et al. 1997). This index will hereafter be called the GI index and its time series was supplied by the Climatic Research Unit (CRU) at the University of East Anglia (www.cru.uea.ac.uk).

\subsection{Indices of extremes and multivariate approach}

The temperature extremes are defined by nonparametric indices that correspond to the percentage of days in each month with Tmin/Tmax above or below a specified threshold. Accordingly, the 90th and 10th percentile thresholds of the empirical distributions of daily variables, calculated for the full time period
(1961-1990) and for each gridbox separately, are used. These quantile levels are indeed feasible thresholds to define, from a statistical viewpoint (Houghton et al. 2001), the domains of extreme episodes. Therefore, the time series of the percentages of days in each month and for each gridbox with Tmin/Tmax below the 10th (above the 90th) percentile is henceforth called the P10 (P90) index. The frequency of occurrence of cold (warm) events is thus measured by the P10 (P90) index.

Although these extremes can be relatively moderate, the choice of more selective thresholds leads to excessively high return periods, which substantially increase the number of zero-occurrences per winter and can bring about misleading results from statistical approaches. A comparison between observed and simulated thresholds revealed similar spatial patterns with minor biases in the percentiles over northeastern Europe (not shown). These biases essentially reflect some inaccuracies in the simulation of the mean fields (not shown). In order to account for these biases, thresholds are independently computed for the observed and simulated recent-past period.

The modes of the coupled variability were then identified by the maximum covariance analysis (MCA), which performs a singular value decomposition of the cross-covariance matrix between the anomalies of a pair of variables (von Storch \& Zwiers 1999). The singular patterns are correlation (covariance) maps between each standardized singular variable, and the respective raw field and loadings are thus dimensionless (anomalies per standard deviation [SD] of the singular variable). The daily anomalies are determined by subtracting the average, calculated for the full time period and for each gridbox, from the raw variables. They are then weighted (by multiplying the anomalies in each grid point by the square root of the respective latitude's cosine) in order to cope with the meridians' convergence.

\section{RESULTS}

\subsection{Observed trends in temperature extremes}

The trends in the occurrence of temperature extremes during the 1961-1990 period, for both Tmin and Tmax, are consistent with the widespread warming recorded over the last few decades (Tank et al. 2002); the frequency of occurrence of P10 extremes (cold events) decreased in a large number of gridboxes (Fig. 1a,c) while the frequency of occurrence of P90 extremes (warm events) tended to increase (Fig. 1b,d). Furthermore, the high resemblance between the trends in Tmin and Tmax for the same type of extremes (P10 

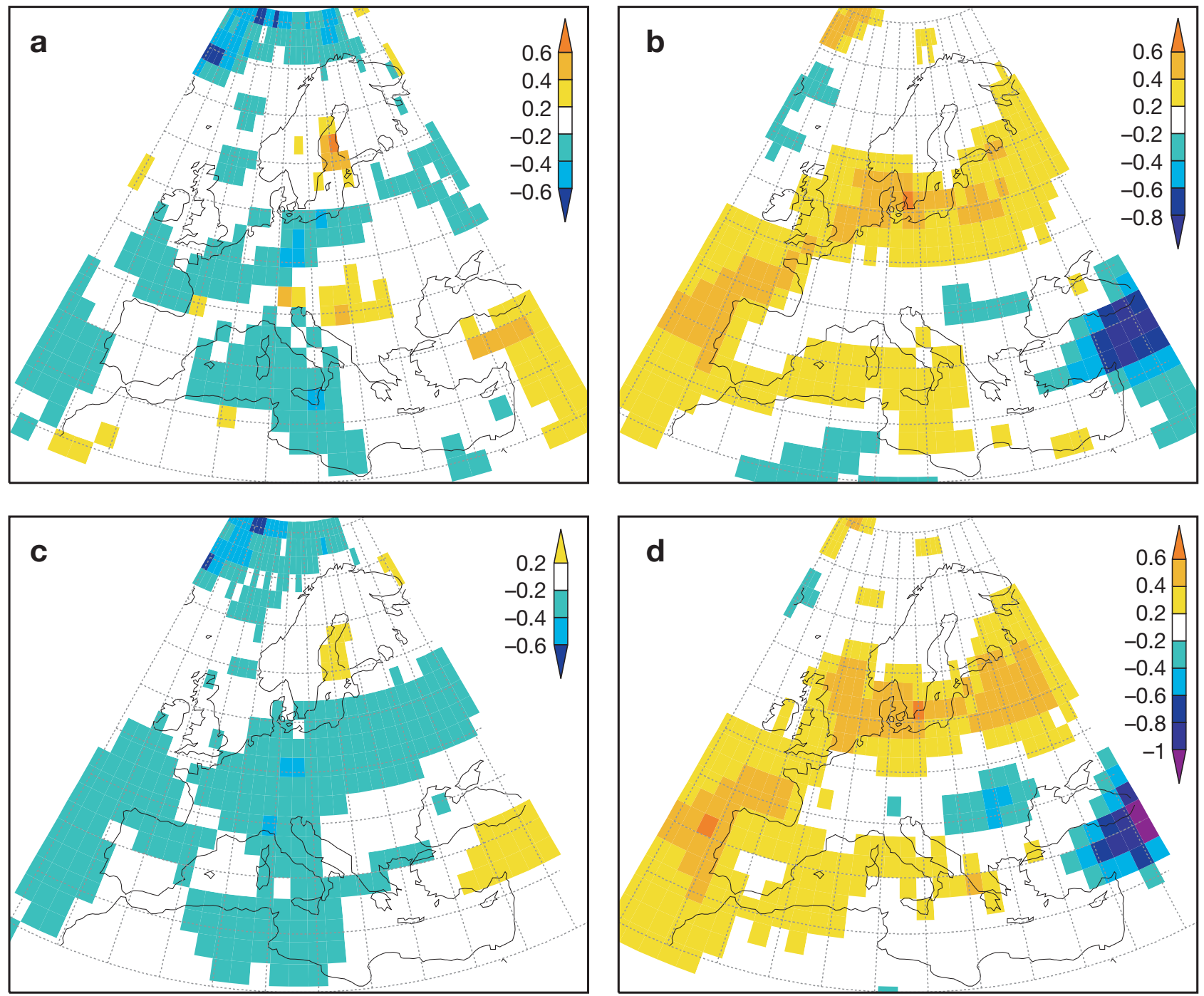

Fig. 1. Linear trends in frequency occurrence of wintertime (DJF) cold events $(a, c)$ and warm events $(b, d)$ in both Tmin (upper panels) and Tmax (lower panels) in reanalyses and for the 1961-1990 period. Values plotted at intervals of $0.2 \mathrm{~d}$ winter ${ }^{-1}$

or P90) suggests that these variables have a parallel behaviour in response to climate change (Fig. 1). In fact, the distributions of Tmin/Tmax experienced a similar warming in their cold and warm tails.

The increase in occurrence of warm events is most noticeable along 2 strips that are joined over Portugal and diverge towards Greece and Russia (Fig. 1b,d). The increase in the number of warm events is also more accentuated over maritime areas, whereas the decrease in occurrence of cold events follows a less defined pattern (Fig. 1a,c). Nevertheless, some gridboxes over the Balkans, Turkey and the Middle East are in clear opposition to the prevailing trends; these regions actually did not experience a significant warming and, in some places, a cooling was recorded instead (Tank et al. 2002).

\subsection{Observed large-scale coupled variability}

Most of these trends might be explained by changes in the coupled variability between the large-scale circulation and occurrence of extreme events. The pressure pattern of the leading coupled mode for both Tmax extremes clearly displays a NAO-like structure, with a phase opposition between the pressure near Iceland and near the Azores (Fig. 2a,c). The occurrence of cold and warm events is thus strongly connected to the NAO forcing. The dominance of this mode in both indices is reflected by the high fractions of explained squared covariance (77\% for the P10 index and $60 \%$ for the P90 index). The correlation coefficient between the first singular variable of the MSLP and the monthly mean GI index is as high as 0.88 (statistically significant 

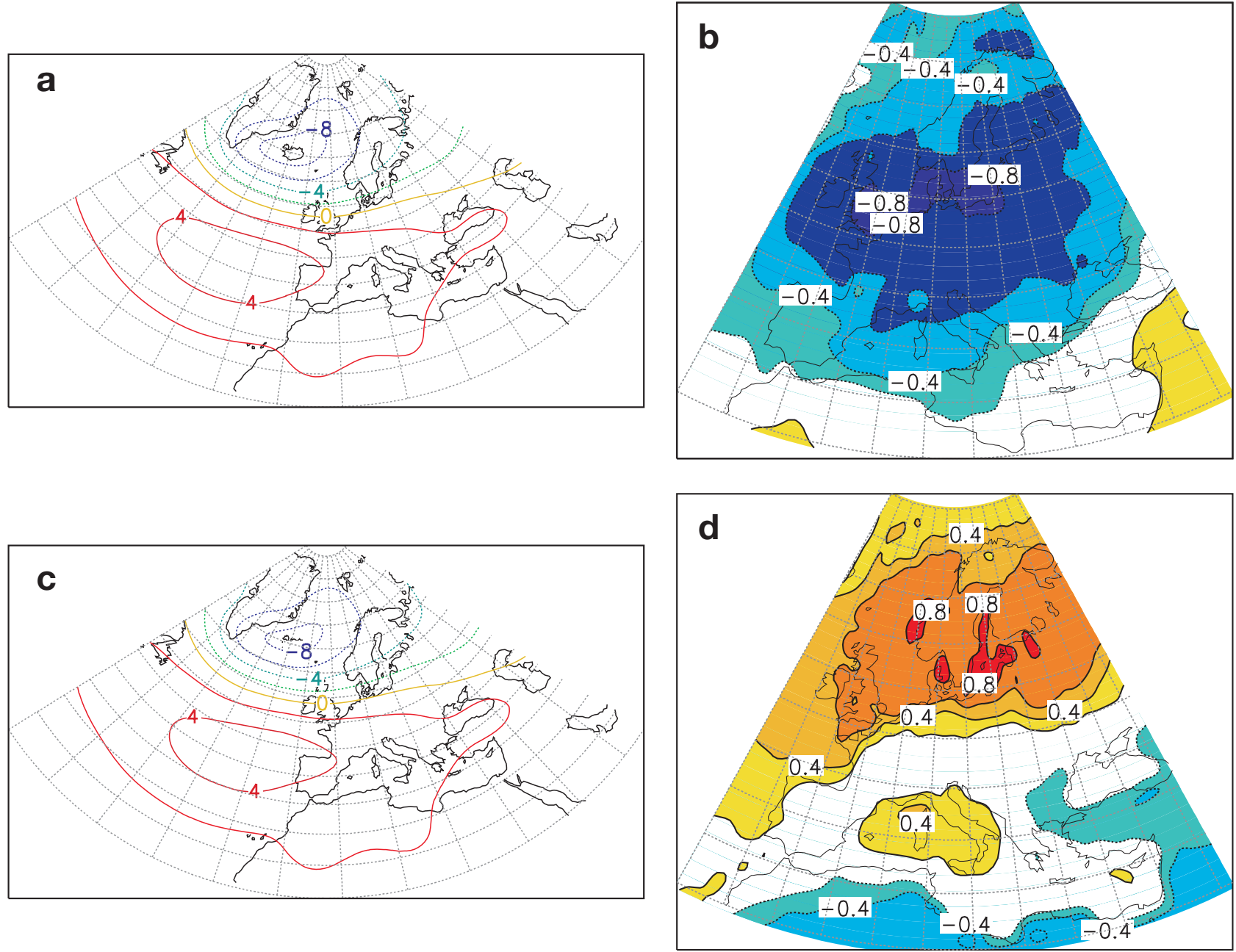

Fig. 2. First singular coupled mode between monthly mean sea level pressure (MSLP) and (a,b) P10 and (c,d) P90 indices for winter Tmax in reanalyses and for the 1961-1990 period. Pressure patterns (left panels) are drawn at intervals of $2 \mathrm{hPa}^{\mathrm{S}} \mathrm{SD}^{-1}$ (SD: standard deviation) and patterns of indices (right panels) are drawn at intervals of 0.2 (dimensionless)

at a confidence level of $99 \%$ ) in both couplings, attesting to the linkage of this mode to the NAO. Furthermore, this leading coupling is almost unchanged when using the linearly de-trended datasets (not shown). In fact, this coupled mode accurately reflects the atmospheric dynamics and is not a mere statistical product attributable to the existing trends.

The P10 pattern shows negative loadings across all of Europe (Fig. 2b), particularly over southern and central Great Britain, Denmark and Southern Sweden, where the occurrence of extremely low temperatures is largely controlled by the NAO phase (negative loadings around 0.8). P10 extremes in Iberia, Greece and northern Scandinavia are less controlled by NAO. Generally speaking, the positive phase of the NAO significantly hampers the occurrence of cold events throughout Europe, while the negative phase provides favourable conditions for their occurrence.
Although the P90 pattern depicts a similar pattern, the occurrence of P90 extremes in several areas of southern and central Europe is much less controlled by the NAO than the occurrence of P10 extremes (Fig. 2c,d). Therefore, despite preventing the occurrence of cold events throughout Europe, the positive phase of the NAO does not govern the occurrence of warm events over some parts of southern and central Europe.

Negative loadings over northern Greece and Bulgaria in both couplings mean that the positive phase of the NAO favours the occurrence of more moderate temperatures than during its negative phase. The signs of the loadings over the Middle East, Turkey and North Africa highlight that prevailing clear sky conditions during the positive phase of the NAO favour anomalously low temperatures, with more cold events and less warm events. 
Similar results were obtained for Tmin and for both indices (not shown). Therefore, in order to avoid redundancy in the presentation of results, more emphasis will be given to Tmax in the forthcoming analyses.

During the negative phase of the NAO, both the Azores high and the Iceland low are anomalously weak (negative patterns of Fig. 2a,c) and the midtropospheric flow over the North Atlantic splits into 2 well-separated branches: a meandering northern branch and a more zonal southern branch (Fig. 3a), a
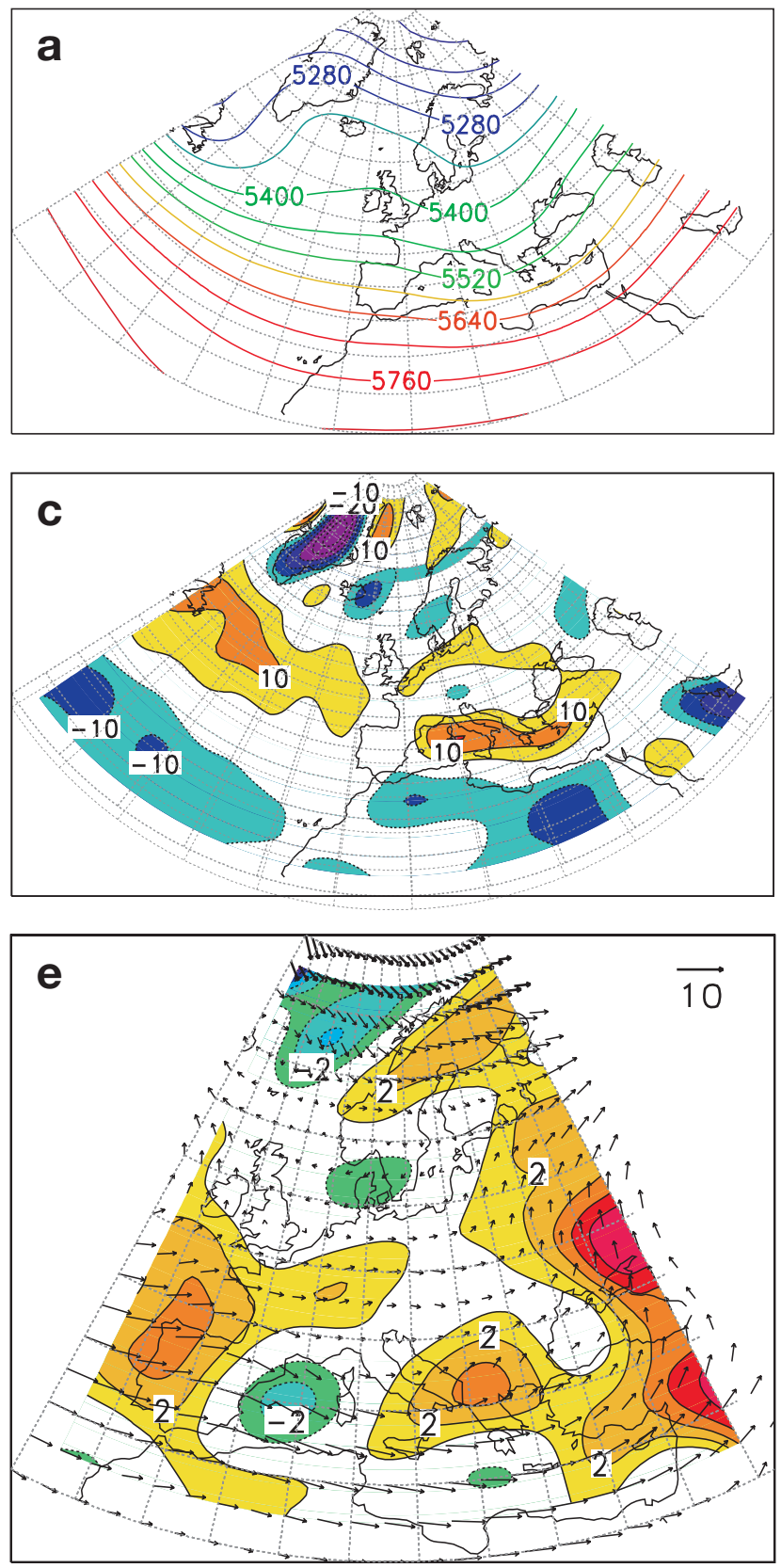

Fig. 3. Composites of $(\mathrm{a}, \mathrm{b})$ geopotential heights at $500 \mathrm{hPa}$ geopotential metres $(\mathrm{gpm}) ;(\mathrm{c}, \mathrm{d})$ relative vertical vorticity in $10^{-6} \mathrm{~s}^{-1}$; and $(\mathrm{e}, \mathrm{f})$ temperature advections $\left(\mathrm{K} \mathrm{d}^{-1}\right)$ and wind $\left(\mathrm{m} \mathrm{s}^{-1}\right)$ at $850 \mathrm{hPa}$ for negative (left panels) and positive (right panels) phases of the first coupled mode in reanalyses and for the 1961-1990 period

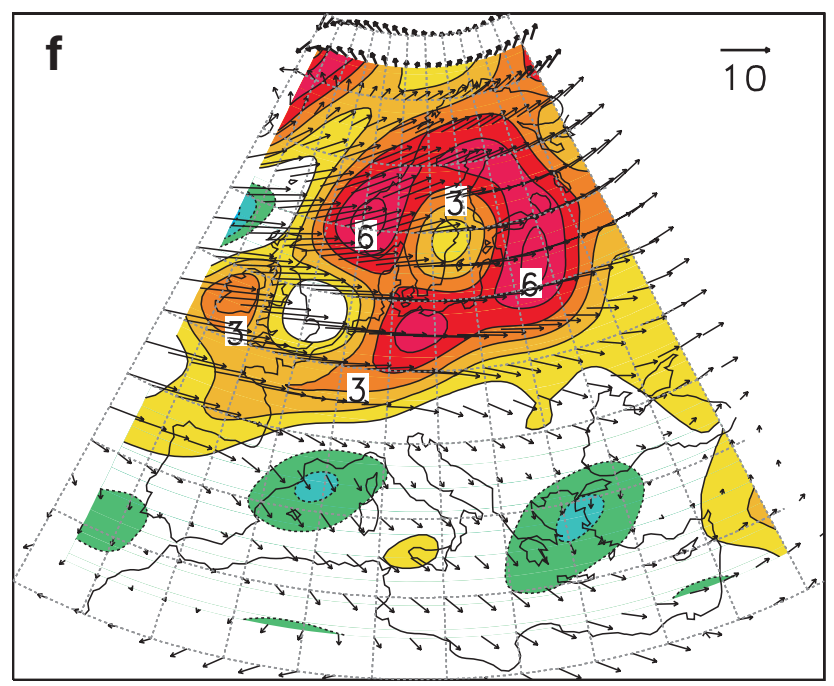

characteristic regime of the North Atlantic blocking (Shabbar et al. 2001). In this phase, cyclones often develop along the southern branch of the westerlies (positive vertical vorticity values in Fig. 3c) and move towards Southern Europe. The cyclonic circulation over the Mediterranean Basin is clearly favoured by the negative phase of the NAO and the subtropical high is displaced southward. The cyclone-driven southerly wind components carry relatively warm air masses over many parts of southern Europe, particu-
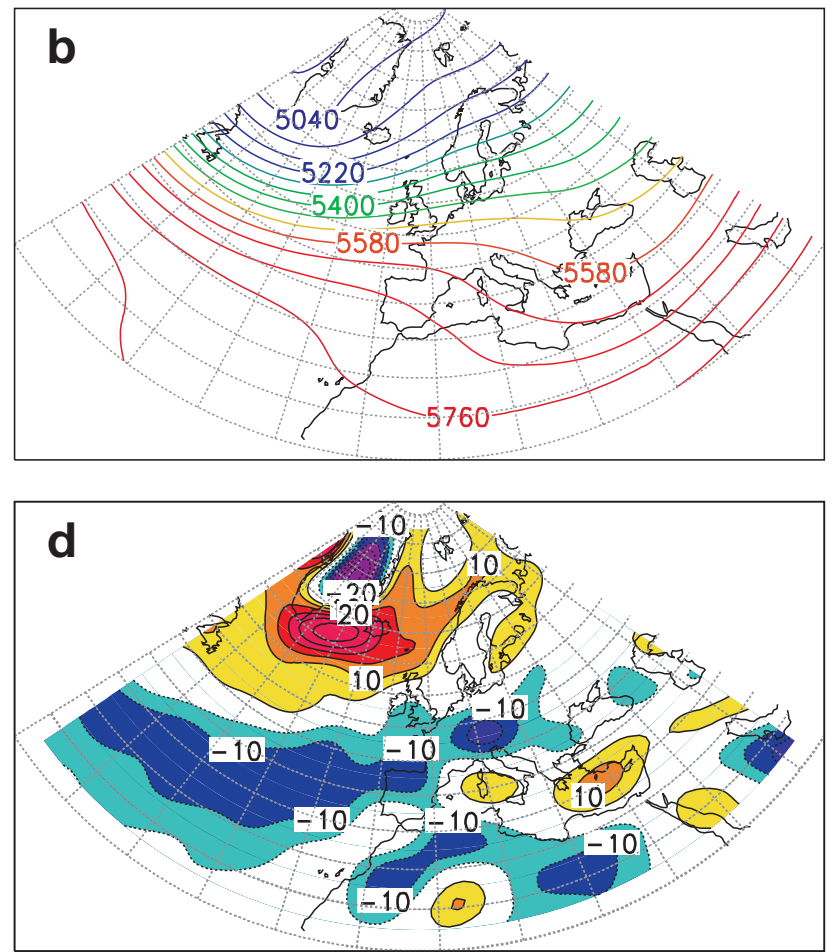
larly over western Iberia, southern Italy, the Balkans, Greece, Turkey and Ukraine (Fig. 3e). The relatively weak winds over northern Europe favour radiative cooling and, in some cases, the easterly and northerly wind components transport cold air masses, resulting in further cooling (Fig. 3e).

In the positive phase of the NAO, both the Azores high and the Iceland low are anomalously strong (positive patterns of Fig. 2a,c). The mid-tropospheric jet stream follows a southwest-northeast path over the North Atlantic towards northern Europe (Fig. 3b). As such, strong cyclones develop near the very south of Greenland and move towards Iceland and the Norwegian Sea (Fig. 3d), while southern and central Europe are mainly exposed to anticyclonic circulation that deviates the storm tracks to the north. The cyclogenesis in the Mediterranean is also reduced. The Azores high is shifted northwards and linked to other anticyclonic areas over western and central Europe. Several studies actually showed that the number of extratropical cyclones in the Euro-Atlantic sector during the positive phase is clearly higher than during the negative phase (Rogers 1990, 1997, Gulev et al. 2002). The strong westerly and southerly wind components over northern and central Europe carry warm air masses, particularly over southwestern Norway (Fig. 3f). In contrast, the prevailing northerly wind components over several regions of southern Europe lead to cold advections.

The development of cyclones is commonly accompanied by the generation of clouds and precipitation that enable diabatic warming through latent heat release. On the contrary, anticyclones are often accompanied by clear skies and strong radiative cooling. Although these processes are not accounted for here, they may still be important in triggering regional temperature anomalies. For instance, the strong warm advections over northeastern Europe in the positive phase of the NAO (Fig. 3f) are reinforced by the release of latent heat in cyclonic developments. On the other hand, the prevailing settled weather conditions in the negative phase of the NAO leads to relatively strong radiative cooling, enhancing the negative temperature anomalies.

Despite the likely relevance of the latter physical mechanisms, the similarity between the composites of the temperature advections (Fig. 3e,f) and the coupling patterns (Fig. 2) highlights the key role of temperature advections in the establishment of the leading coupling. Hence, the occurrence of temperature extremes in Europe, particularly in its northern half, is clearly associated with NAO-driven anomalies in temperature advections.

The second coupled mode is still significant regarding the occurrence of both cold and warm events (Fig. 4). Here again, due to the great resemblance between the patterns for Tmin and Tmax, only the patterns for Tmax are shown. This mode is unrelated to the NAO (correlation coefficients between the singular variables of the MSLP and GI index are roughly zero). The second order coupled mode for P10 extremes is weaker than for P90 extremes (10 against $22 \%$ of total explained squared covariance) and the first 2 modes cumulatively explain about 86 and $82 \%$ of the total squared covariance, respectively. The remaining modes reflect smaller scale features that might not be reliable, due to the relatively coarse grids and to the inherent properties of the statistical approach.

Besides the NAO forcing, the occurrence of cold events over Iberia and over the western and central Mediterranean is strongly related to the presence of blocking highs westward of the British Isles - i.e. the negative phase of the second coupled mode for the P10 index (Fig. 4a,b) - through the transport of cold air masses from northern and central Europe. Conversely, the occurrence of cold events over Scandinavia appears to be favoured by low pressure systems westward of the British Isles and relatively high pressures over Scandinavia. On the other hand, the occurrence of warm events over most of Europe, especially over southern and central Europe, is favoured by low pressure systems westward of the British Isles (Fig. 4c,d).

The joint contribution of the first 2 coupled modes to the variability of each index can be measured by the local percentages of variance explained by these 2 modes. These fractions correspond to the square of the multiple determination coefficient of a bivariate linear regression model, where the first 2 singular variables are predictors of the index at each gridbox. The first 2 modes represent more than $20 \%$ of the total variance of both indices over almost all of Europe (Fig. 5). Nonetheless, higher fractions (up to $70 \%$ ) are clearly lined up along a southwest-northeast tilted strip that extends from northern Iberia to Russia. Other maximums emerge over the western and central Mediterranean. The insignificant contribution of these 2 modes for the variability in the occurrence of cold events in the eastern Mediterranean, Turkey and the Middle East is worth mentioning.

The chronograms of the singular variables of the first mode depict upward trends in both extremes and in both Tmin and Tmax (Fig. 6), which are supported by the strengthening of the positive phase of the NAO (Hurrell 1996). The NAO forcing in the occurrence of temperature extremes and in their trends is confirmed by the high correspondence between the singular variables of both extremes and the corresponding singular variable of the MSLP. The high degree of resemblance between the coupled modes of the extremes in Tmin and Tmax is corroborated by the close variability of the respective singular variables. 

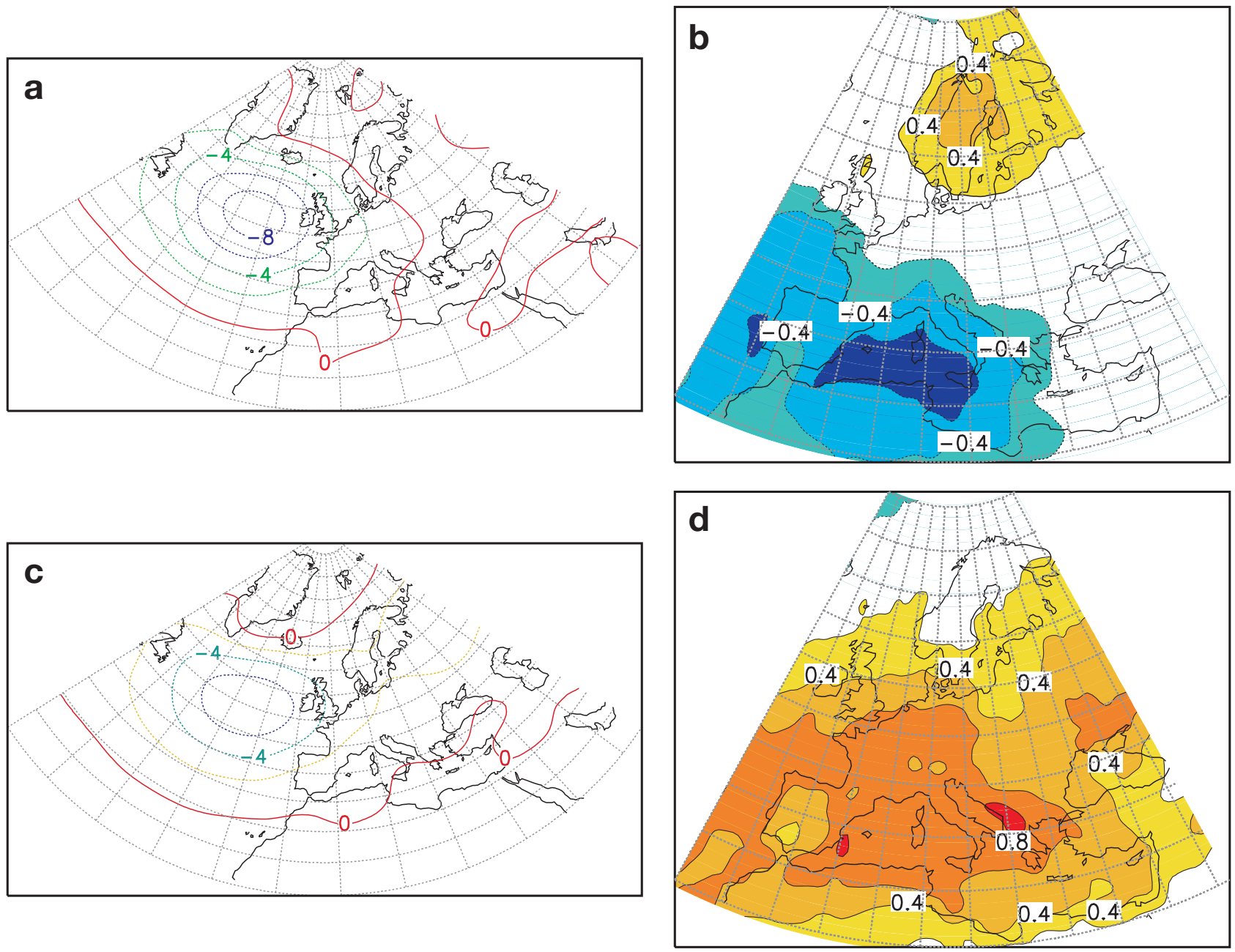

Fig. 4. As for Fig. 2, but relating to the second coupled mode
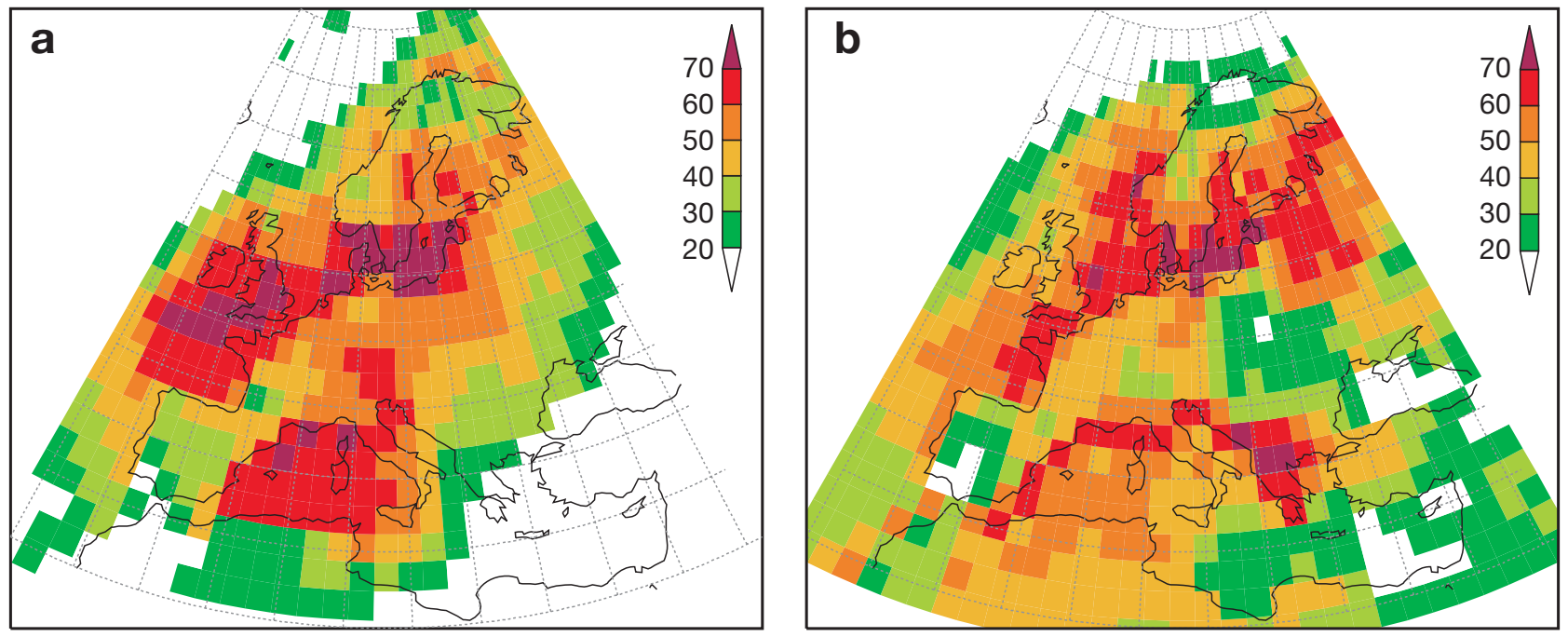

Fig. 5. Percentages of variances of the (a) P10 and (b) P90 indices for Tmax, represented by the first 2 coupled modes in reanalyses and for the 1961-1990 period. Values plotted at intervals of $10 \%$ and are omitted below $20 \%$ 

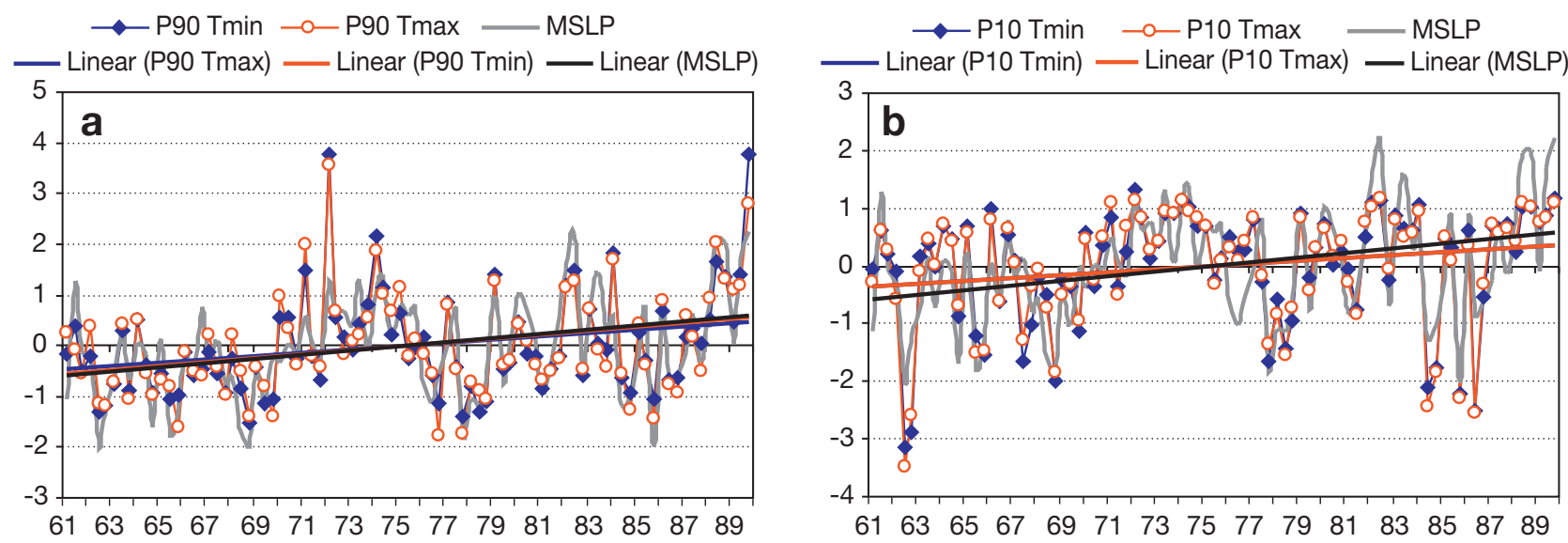

Fig. 6. Chronograms of the first singular variables of (a) P10 and (b) P90 indices for reanalyzed Tmin and Tmax, $1961-1990$. Corresponding first singular variable of the MSLP is also plotted in each graph. Respective least-squares linear trends are also displayed. Linear (P10 Tmin) trend (blue line) in (b) is hidden by Linear (P10 Tmax) trend (orange line). All time series are standardized to 0 mean and unit variance

The upward trend in the singular variables of P10 implies a decrease (negative loadings in Fig. 2b) in the frequencies of occurrence of cold events throughout Europe, which is in overall agreement with Fig. 1c. The upward trend in the singular variables of P90 implies an increase (positive loadings in Fig. 2d) in the frequencies of occurrence of warm events over northern Europe and over the central and western Mediterranean, which is now in accordance with Fig. 1d. Therefore, the strengthening of the positive phase of the NAO-and of the leading large-scale coupling - triggered most of the trends in the occurrence of temperature extremes in Europe (Fig. 1).

The strong variability of the singular variables is also noteworthy and is accentuated by some very pronounced extremes. For instance, the singular variable of the P90 extremes in Tmin reaches scores almost 4 times higher than the corresponding SD in December 1972 and February 1990; in the first month, positive anomalies in the monthly mean temperature, higher than $4^{\circ} \mathrm{C}$, were recorded over northeastern Europe, whilst in the second month similar anomalies were recorded not only in this region, but also over central Europe and the western Mediterranean (not shown). The singular variable of the P10 extremes in Tmin also reaches a rather prominent negative score in January 1963; this month was anomalously cold all across Europe, especially over central Europe, with negative temperature anomalies higher than $6^{\circ} \mathrm{C}$ (not shown).

All the above mentioned trends are statistically significant according to the Mann-Kendall and Spearman tests (Sneyers 1975) applied at a significance level of $1 \%$. Despite the slightly upward trends in the singular variables of the second mode (not shown), none of them are statistically significant. Lastly, the apparent skew of the singular variables can be attributed to the sporadic occurrence of very intense cold and warm outbreaks, which generate highly anomalous atmospheric conditions. The occurrence of winter temperature extremes in Europe is thus strongly related to the first 2 coupled modes, and their recent-past trends are mainly a result of the enhancement of the north-south pressure gradient in the Euro-Atlantic sector.

\subsection{GCM simulated couplings and future scenarios}

The pattern of changes in the winter mean Tmax gives clear proof of a strong projected warming throughout Europe (Fig. 7). Moreover, the stronger radiative forcing in the $\mathrm{A} 2$ scenario relative to the $\mathrm{B} 2$ scenario is also noticeable. Under A2, the warming is especially intense over northeastern Europe, where increases higher than $8^{\circ} \mathrm{C}$ are predicted to occur, while northwestern Europe and the Mediterranean experience much lesser changes. No significant changes in SD were simulated under either emission scenarios, except over a few grid boxes in northeastern Europe (not shown). This means that the key factor for the increase in the occurrence of warm events is the increase in mean Tmax, while changes in the width of the distributions play an insignificant role. The strong warming over northeastern Europe throughout the 21st century, under B2 and A2 SRES emission scenarios, was also reported in previous studies that used HadCM3 as a global driving model in regional simulations (e.g. Giorgi et al. 2004, Raisanen et al. 2004).

Although the highest Tmax increases are found over northeastern Europe, the local relative relevance of these increases is offset by large variances. Conversely, comparatively small changes over several maritime regions, with low variances, can be quite significant. 

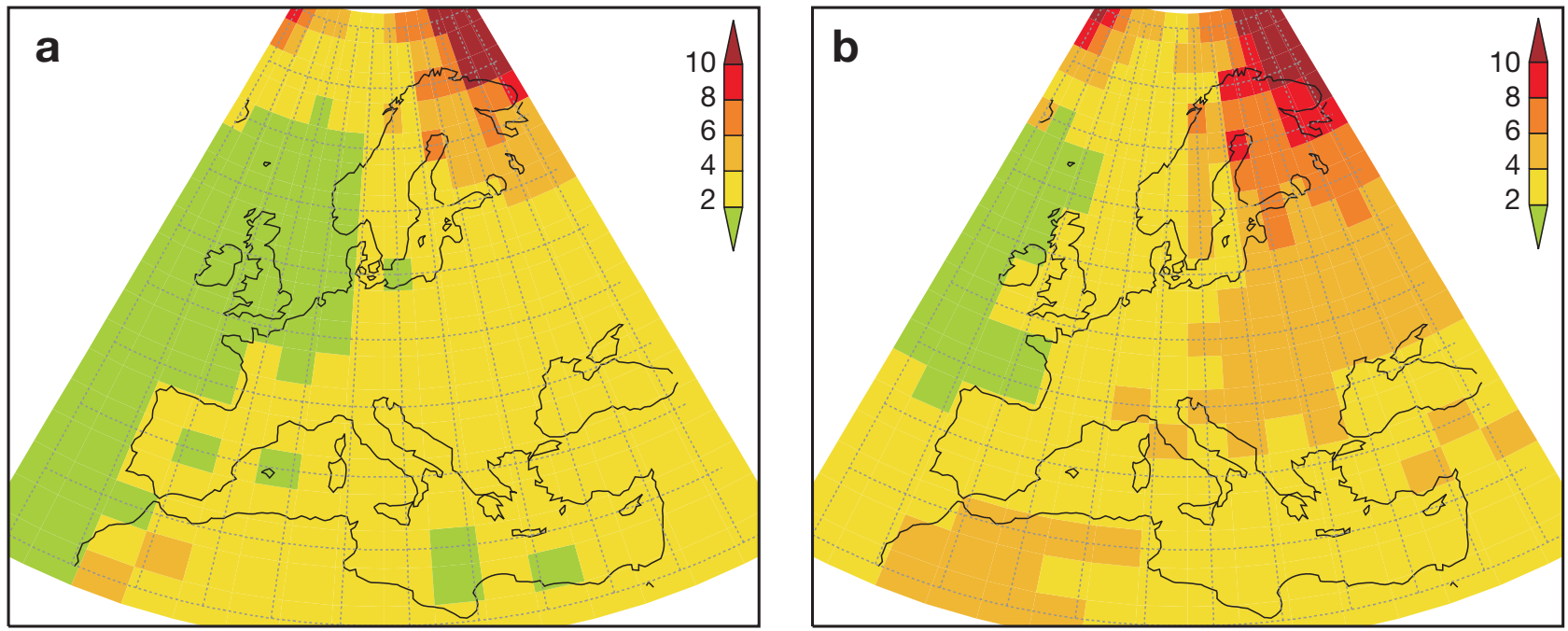

Fig. 7. Changes in wintertime (DJF) mean Tmax under the (a) B2 and (b) A2 SRES emission scenarios between the future period (2070-2099) and reference period (1961-1989), projected by HadCM3. Values plotted at intervals of $2^{\circ} \mathrm{C}$

The changes in the frequency of occurrence of warm events thereby tend to be higher over maritime areas (not shown). This pattern is actually similar to the pattern of the trends in the recent-past period (Fig. 1d), except over the Balkans and the Middle East, where the warm events are also projected to increase in future scenarios. This result supports the hypothesis that recently recorded trends are partially due to anthropogenic forcing.

Even over continental areas and in the B2 scenario (weaker forcing), the mean P90 index undergoes absolute increases $>20 \%$; an increase of $20 \%$ in the mean P90 index (with an average of $10 \%$ in the simulated common period in all grid boxes) signifies that the 90th percentile threshold in the recent-past period corresponds to the 70th percentile of the temperature distribution in the future period. Additionally, the warming leads to a near absence of cold events, which are thus dropped in the assessment of future changes. Similar results were obtained for Tmin (not shown). Hence, winter warming in Europe is manifested by an overall increase in both Tmin and Tmax, and the frequencies of occurrence of extremely high (low) values are projected to significantly increase (decrease) by the end of the 21st century.

The warming patterns reveal that the extra energy supplied by the enhanced greenhouse effect is unevenly distributed, which might be attributed to largescale couplings. In fact, both the highest loadings in Fig. $2 \mathrm{~d}$ and the highest temperature anomalies in Fig. 7 tend to be located over northeastern Europe, which suggests that the NAO forcing may be responsible for the distribution of a large amount of this extra energy. Therefore, the reliability of the warming pat- terns critically depends on the ability of HadCM3 to reproduce the NAO forcing. Moreover, changes in the NAO forcing under modified climatic conditions can provide further insight into the climate change signal. It is thus important to not only assess the skill of HadCM3 in reproducing the aforementioned couplings, but also to investigate their likely changes under altered climates.

The simulated leading coupled mode for the P10 extremes in Tmax explains about $59 \%$ of the total squared covariance, against $77 \%$ in reanalyses. The MSLP pattern is skilfully simulated, apart from an underestimation of the anomalies in the northern $\mathrm{COA}$ (about $3 \mathrm{hPa} \mathrm{SD}{ }^{-1}$ ). This latter shortcoming is also detected in the NAO pattern itself (not shown) and is explained by the underestimation of the pressure variance over this region (not shown). In fact, HadCM3 is unable to accurately reproduce the observed variability of the daily MSLP fields in the Iceland low area (Santos 2005). There are also significant differences in the pattern of the P10 index over the Mediterranean Basin when compared to reanalyses (Figs. 2a \& 8a). Therefore, the model presents some limitations in the simulation of this coupling, and this result decreases the significance of the projected changes in the P10 index.

The simulated leading coupled mode for the P90 extremes in Tmax (Fig. 8d) explains $62 \%$ of the total squared covariance (nearly the same as in reanalyses) and its patterns are in clear agreement with the corresponding patterns in reanalyses. Apart from the abovementioned deficiency in the simulation of northern COA in the MSLP pattern (Fig. 8c), the P90 pattern reveals slight underestimations of the sensitivity of P90 

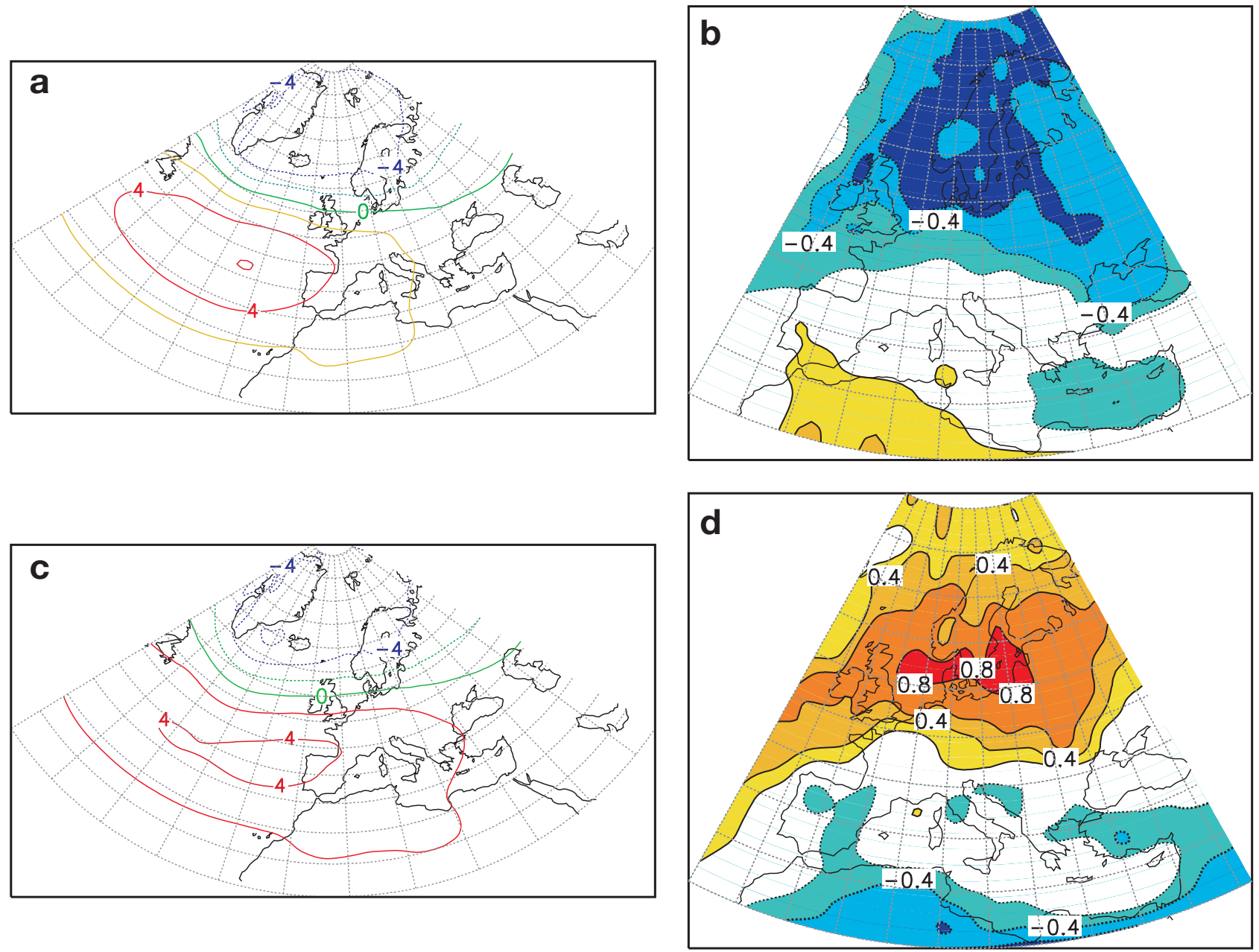

Fig. 8. As for Fig. 2, but relating to the reference period simulated by HadCM3 (1961-1989)

extremes to the NAO phase (lower loadings) over some parts of the western and central Mediterranean (Fig. 8d). The second coupled mode is also consistently reproduced (not shown). Therefore, HadCM3 is skilful in replicating the large-scale coupling for the P90 extremes, but is less able to do so in the case of the P10 extremes. However, due to the already mentioned sharp decrease in the occurrence of extremely low temperatures in the future, the coupling for the P10 index is of secondary relevance in the assessment of future changes. Therefore, the next step is the assessment of how the leading coupling for the P90 extremes is projected to change under human-induced radiative forcing.

Due to the strong warming in both scenarios (Fig. 7), the entire temperature distributions experience a significant shift to higher temperatures. In this manner, and in order to maintain the analysis focused on extreme events (cold and warm tails of the distributions), the percentile thresholds were recalculated for the future period and for each scenario separately. The lead- ing coupled mode for the P90 extremes in Tmax under the B2 and A2 scenarios (2070-2099) is displayed in Fig. 9. The eastward extension of the southern COA in the MSLP pattern is the most remarkable change under both emission scenarios (Fig. 9a,c). The explained squared covariance increases in B2 (from 62 to $76 \%$ ) and decreases in A2 (from 62 to $52 \%$ ). The slight weakening of the NAO forcing in A2, which appears to be in contradiction with the strong changes in radiative forcing, is discussed in the next subsection (Section 3.4).

As a response to the projected changes in the largescale flow, the positive loadings in the P90 pattern and B2 scenario undergo an overall enhancement, particularly over northern Europe (Fig. 9b). In the A2 scenario, they also experience a significant extension towards southwestern Europe (Fig. 9d). The negative loadings over Iberia are projected to be replaced by positive loadings in the A2 scenario, which is a response to the displacement of the high pressure area from the North Atlantic towards the Mediterranean. Therefore, according to the analyzed scenarios, the 

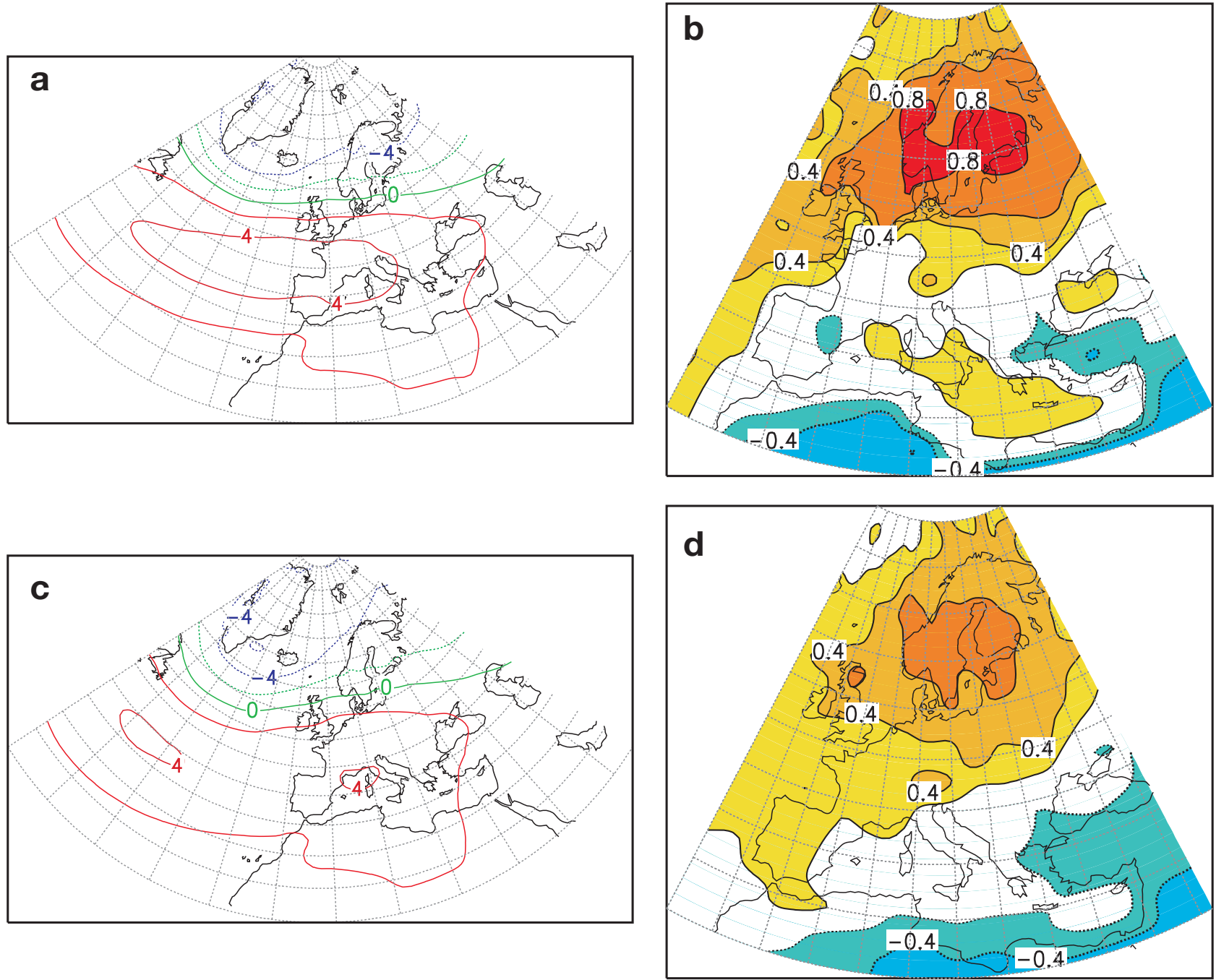

Fig. 9. As for Fig. 2, but relating to the future period (2070-2099) in the (a,b) B2 and (c,d) A2 SRES emission scenarios and only for the P90 index

positive phase of the 'modified NAO' is essentially favourable to the occurrence of warm events throughout Europe.

The results discussed in the previous paragraph suggest that the strength of the NAO forcing critically depends on the emission scenario as it responds non-linearly to the radiative forcing. A more detailed analysis revealed that changes in the temperature advections over Europe are coherent with changes in the patterns of the warm events (not shown). In this way, for a specific region, the connection between the occurrence of warm events and the NAO critically depends on the emission scenario. These findings hint at the high complexity and uncertainty involved in the assessment of future scenarios for temperature extremes.

The eastward extension of the southern COA is also apparent in the first empirical orthogonal function (suitable indicator of the NAO) of both the monthly and daily MSLP within the Euro-Atlantic sector (not shown). The projected changes in the leading coupling are thus plainly coherent with the changes in the characteristic pattern of the NAO and are definitely not due to a statistical artefact. In addition, the strong wintertime stratosphere-troposphere coupling (Perlwitz \& Graf 1995, 2001, Monahan et al. 2003) suggests that the projected changes in the NAO pattern in the lower troposphere must be accompanied by consistent changes in the upper tropospheric flow and in the stratosphere.

\subsection{Troposphere-stratosphere interaction}

The leading coupled mode between the geopotential height at $850 \mathrm{hPa}$ (lower troposphere) and at $50 \mathrm{hPa}$ (lower stratosphere) in the simulated recent-past period (Fig. 10a,b) is similar to the corresponding mode in 

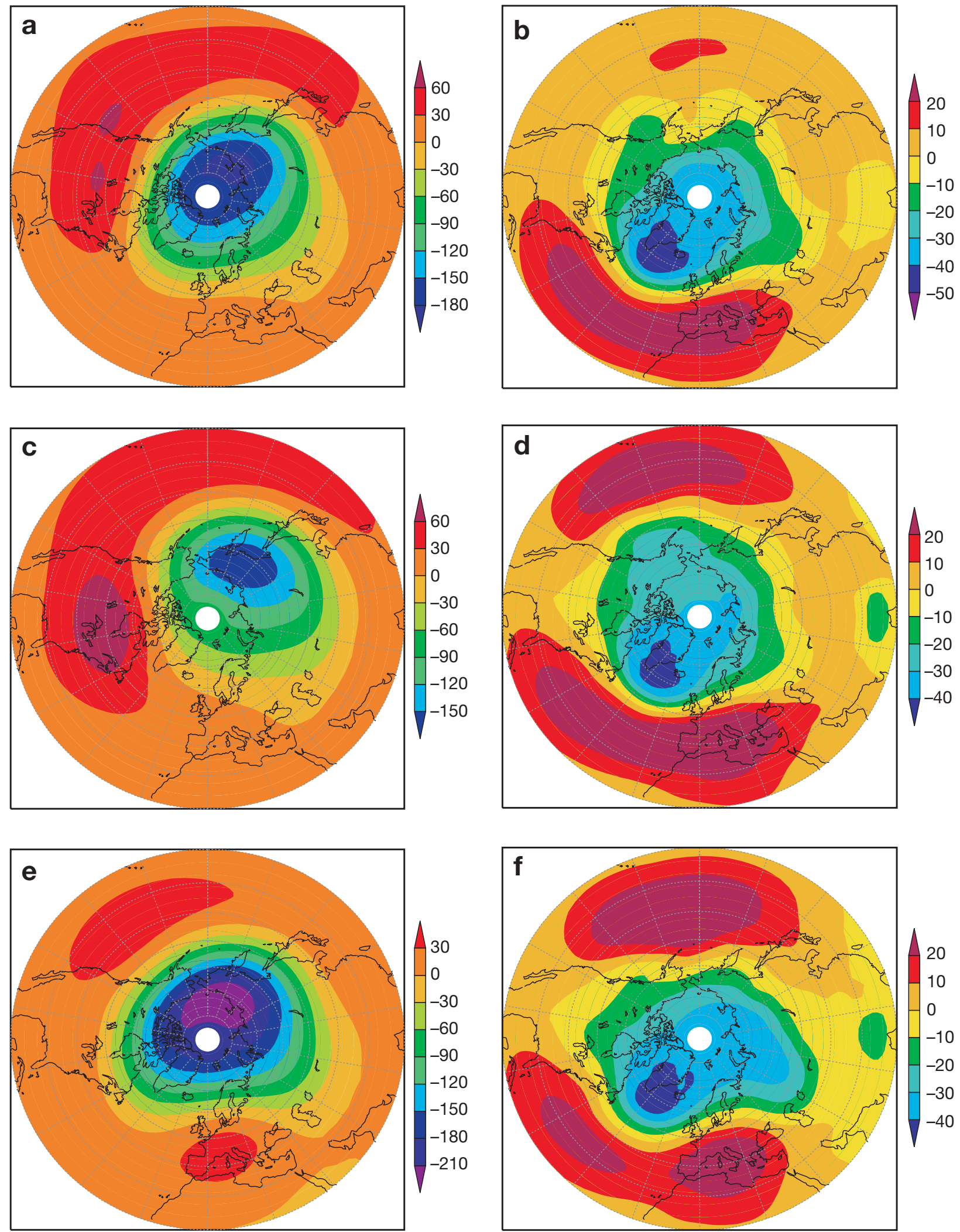

Fig. 10. First singular coupled modes in HadCM3 data between wintertime (DJF) monthly mean geopotential heights at 50 hPa (left panels) and at $850 \mathrm{hPa}$ (right panels) in (a,b) the reference period (1961-1989) and the future period (2070-2099) under the $(c, d)$ B2 and $(e, f)$ A2 SRES emission scenarios 
reanalyses (not shown), which highlights the reliability of the simulated large-scale stratospheric and tropospheric flows. This mode uncovers a strong coupling between the strength of the stratospheric polar night jet (PNJ) and the NAO, and explains about $65 \%$ of total squared covariance between both atmospheric fields. It is also a clear expression of the Northern Annular Mode/Artic Oscillation (Thompson \& Wallace 1998, 2000a,b).

The projected changes in the troposphere-stratosphere coupled system are highly consistent with the projected changes in the NAO and in the respective forcing over the occurrence of warm events (Figs. 9a,c \& 10e,f). Under the B2 scenario (Fig. 10c,d), the PNJ undergoes major changes, including a large shift in the position of its coldcore towards eastern Siberia and a weakening of its strength over Europe. The southern COA of the NAO appears to experience an enhancement over the Mediterranean Basin and central Europe, leading to a northward displacement of negative anomalies over Northern Europe. Under the A2 scenario (Fig. 10e,f), the strength of the PNJ over northern Europe increases (stronger meridional gradient in the geopotencial anomalies) and a deep ridge emerges over the continent. The southern COA appears to be split into 2 parts: one COA over the North Atlantic and another over the Mediterranean Basin. This mode explains about 56\% (70\%) in the B2 (A2) scenario, which is not a substantial change when compared to the recent-past period $(65 \%)$. The enhancement of the positive COA in the low troposphere over the North Pacific is still remarkable, even though it has no direct effect on the occurrence of extremes in Europe.

It is still worth mentioning that the mean meridional gradient of the geopotential height (strength of mean PNJ) increases under both scenarios, particularly in A2. This enhancement is primarily as a result of an increase in the thickness of the $50-850 \mathrm{hPa}$ layer over low latitudes (not shown), which may be related to an intensification of the wintertime differential warming between low and high latitudes as a result of the enhanced greenhouse effect.

Therefore, the PNJ and the troposphere-stratosphere coupling are stronger in A2 than in B2. However, the above-described split of the southern COA of the NAO in A2 (Figs. 9c \& 10f) leads a decrease in the absolute covariability between this modified oscillation and the frequencies of occurrence of warm events all across Europe. In fact, the NAO forcing is projected to undergo such a significant reshaping that its role in the explanation of total covariance decreases (from 62 to $52 \%$ ) and the forcing over the occurrence of extremes weakens.

\section{SUMMARY AND CONCLUSIONS}

The occurrence of temperature extremes in Europe for both Tmin and Tmax were calculated for each winter month (DJF) on a daily basis. It was shown that during the reference period (1961-1990) the number of cold events decreased and the number of warm events increased, which is a result of widespread warming recorded during this period. Even though trends in both Tmin and Tmax are largely similar, the trends in the occurrence of warm and cold events do not follow the same pattern. The upward trend in the number of warm events tends to be more pronounced over maritime regions, while the downward trend in the number of cold events is more spread out across Europe. Opposite trends were identified in the Balkans, Turkey and the Middle East. The spatial coherence of the trends is still noteworthy and their patterns are consistent with previous studies (Tank et al. 2002). The simultaneous warming of the warm and cold tails of the distributions of daily minimum and maximum temperatures is in clear agreement with previous results obtained from station data (Tank \& Konnen 2003, Moberg \& Jones 2005). Much of this warming has also been related to anthropogenic emissions of greenhouse gases (e.g. Jones et al. 2003).

The NAO forcing is the dominant influence on the occurrence of temperature extremes, in both cold and warm events and in both Tmin and Tmax. This forcing is particularly clear in northern Europe and in the western and central Mediterranean. This coupling is mainly due to strong anomalies in the large-scale advections that lead to anomalous daily temperatures and eventually to extreme events. On the whole, the positive phase of the NAO favours the occurrence of warm events in Europe, particularly over its northern half, whereas the negative phase of the NAO favours the occurrence of cold events over almost all of Europe. Furthermore, the enhancement of the NAO forcing during the reference period underlies the trends in the occurrence of temperature extremes in Europe.

The observed upward trend in the NAO index is not reproduced by HadCM3 in the recent-past period, which is also in agreement with previous findings (Collins et al. 2001). According to this model, the mean temperature throughout Europe is projected to increase from $1^{\circ} \mathrm{C}$ up to more than $10^{\circ} \mathrm{C}$ by the end of the 21st century; this warming is particularly significant over northeastern Europe and under the A2 scenario. As a result of the increase in mean temperatures (changes in variance are irrelevant), the frequencies of occurrence of warm events are projected to sharply increase, which might have severe impacts on the environment and in numerous socio-economic systems. These extremes have particularly high impacts 
in agriculture and forest management, in the frequency of avalanches and snow-melting in mountainous areas like the Alps (Beniston 2005), in the tourism industry, in the storm damage of forests favoured by early thawing of soils (Nilsson et al. 2004), and in the frequency of temperature backlashes that may cause frost damage (Jonsson et al. 2004).

Nevertheless, the projected warming is also accompanied by significant changes in the general atmospheric circulation and in the stratosphere-troposphere coupled system, which are reliably simulated by HadCM3 (Collins et al. 2001). The eastward extension of the southern COA of the NAO in the pressure pattern is the most remarkable change, which directly affects regional/local linkages between the occurrence of warm events and the NAO. On the whole, the eastward extension of the southern COA means that the positive phase of the future 'modified NAO' is likely to provide favourable conditions for the occurrence of warm events over almost all of Europe. This latter result is markedly different from the currently observed conditions over most of southern Europe.

The frequency of occurrence of extreme episodes critically depends on the large-scale circulation, constraining the reliability of impact studies to the reliability of the simulated large-scale circulation under modified climatic conditions. These outcomes stress the high complexity involved in the assessment of future climatic scenarios with regard to extremes. Although the present study is focused on HadCM3 data, it must be kept in mind that other models might still lead to different changes in the large-scale forcing. Nevertheless, there is evidence of a high consistency among several state-of-the-art models with respect to the strengthening of the Northern Annular Mode under radiative forcing (Rauthe et al. 2004).

Acknowledgements. This research was developed under the EC project MICE (Modelling the Impact of Climate Extremes), contract number EVK2-CT-2001-00118. Part of the dataset was provided by the Climate Impacts LINK project, funded by the UK Department of the Environment, Food and Rural Affairs (contract reference EPG 1/1/154). All maps were produced by the Grid Analysis and Display System developed at the Center for Ocean-Land-Atmosphere Interactions.

\section{LITERATURE CITED}

Barnston AG, Livezey RE (1987) Classification seasonality and persistence of low-frequency atmospheric circulation patterns. Mon Weather Rev 115:1083-1126

Beniston M (2004) The 2003 heat wave in Europe: a shape of things to come? An analysis based on Swiss climatological data and model simulations. Geophys Res Lett 31: 2022-2026, doi:10.1029/2003GL018857

Beniston M (2005) Warm winter spells in the Swiss Alps: strong heat waves in a cold season? A study focusing on climate observations at the Saentis hight mountain site. Geophys Res Lett 32:1812-1817, doi:10.1029/2004 GL021478

Black E, Blackburn M, Harrison G, Hoskins B, Methven J (2004) Factors contributing to the summer 2003 European heatwave. Weather 59:217-223

Collins M, Tett SFB, Cooper C (2001) The internal climate variability of HadCM3, a version of the Hadley Centre coupled model without flux adjustments. Clim Dyn 17: $61-81$

Corte-Real JM, Wang X, Zhang X (1995a) Modes of variability in the Northern Hemisphere's mid tropospheric largescale circulation. Theor Appl Climatol 50:133-146

Corte-Real J, Zhang X, Wang X (1995b) Downscaling GCM information to regional scales: a non-parametric multivariate regression approach. Clim Dyn 11:413-424

Corte-Real J, Qian B, Xu H (1999) Circulation patterns, daily precipitation in Portugal and implications for climate change simulated by the second Hadley Centre GCM. Clim Dyn 15:921-935

Fink AH, Brücher T, Krüger A, Leckebusch GC, Pinto JG, Ulbrich U (2004) The 2003 European summer heatwaves and drought-synoptic diagnosis and impacts. Weather 59:209-216

Giorgi F, Bi X, Pal JS (2004) Mean, interannual variability and trends in a regional climate change experiment over Europe. I. Present-day climate (1961-1990). Clim Dyn 22: 733-756

Gulev SK, Jung T, Ruprecht E (2002) Climatology and interannual variability in the intensity of synoptic-scale processes in the North Atlantic from the NCEP-NCAR reanalysis data. J Clim 15:809-828

Houghton JT, Ding Y, Griggs DJ, Noguer M, van der Linden PJ, Dai X, Maskell K, Johnson CA (2001) Climate change 2001: the scientific basis. Contribution of Working Group I to the Third Assessment Report of the Intergovernmental Panel on Climate Change. Cambridge University Press, New York

Hulme M, Osborn TJ, Johns TC (1998) Precipitation sensitivity to global warming: comparison of observations with HadCM2 simulations. Geophys Res Lett 25:3379-3382

Hurrell JW (1996) Influence of variations in extratropical wintertime teleconnections on Northern Hemisphere temperatures. Geophys Res Lett 23:665-668

Hurrell JW, Kushnir Y, Visbeck M (2001) The North Atlantic oscillation. Science 291:603-605

Johns TC, Gregory JM, Johnson CE, Jones A and 7 others (2003) Anthropogenic climate change for 1860 to 2100 simulated with the HadCM3 model under updated emission scenarios. Clim Dyn 20:583-612

Jones PD, Moberg A (2003) Hemispheric and large-scale surface air temperature variations: An extensive revision and an update to 2001. J Clim 16:206-223

Jones PD, Jonson T, Wheeler D (1997) Extension to the North Atlantic Oscillation using early instrumental pressure observations from Gibraltar and south-west Iceland. Int J Climatol 17:1433-1450

Jones GS, Tett SFB, Stott PA (2003) Causes of atmospheric temperature change 1960-2000: a combined attribution analysis. Geophys Res Lett 30:1228-1236, doi:10.1029/ 2002GL016377

Jonsson AM, Linderson ML, Stjernquist I, Schlyter P, Barring L (2004) Climate change and the effect of temperature backlashes causing frost damage in Picea abies. Global Planet Change 44:195-207

Kalnay E, Kanamitsu M, Kistler R, Collins W and 18 others (1996) The NCEP/NCAR 40-year reanalyses project. Bull Am Meteorol Soc 77:437-471 
Kiktev D, Sexton DMH, Alexander L, Folland CK (2003) Comparison of modelled and observed trends in indices of daily climate extremes. J Clim 16:3560-3571

Leckebusch GC, Ulbrich U (2004) On the relationship between cyclones and extreme windstorm events over Europe under climate change. Global Planet Change 44:181-193

Luterbacher J, Dietrich D, Xoplaki E, Grosjean M, Wanner H (2004) European seasonal and annual temperature variability, trends, and extremes since 1500. Science 303:1499-1503

Moberg A, Jones PD (2005) Trends in indices for extremes in daily temperature and precipitation in central and western Europe, 1901-99. Int J Climatol 25:1149-1171

Monahan AH, Fyfe JC, Pandolfo L (2003) The vertical structure of wintertime climate regimes of the Northern Hemisphere extratropical atmosphere. J Clim 16:2005-2021

Nakicenovic N, Swart R (2000) Special report on emission scenarios: a special report of Working Group III of the Intergovernmental Panel on Climate Change. Cambridge University Press, Cambridge

New M, Todd M, Hulme M, Jones P (2001) Precipitation measurements and trends in the twentieth century. Int $\mathrm{J}$ Climatol 21:1899-1922

Nilsson C, Stjernquist I, Barring L, Schlyter P, Jonsson AM, Samuelsson H (2004) Recorded storm damage in Swedish forests 1901-2000. For Ecol Manage 199:165-173

Osborn TJ, Briffa KR, Tett SFB, Jones PD, Trigo RM (1999) Evaluation of the North Atlantic oscillation as simulated by a coupled climate model. Clim Dyn 15:685-702

Perlwitz J, Graf HF (1995) The statistical connection between tropospheric and stratospheric circulation of the Northern Hemisphere in winter. J Clim 8:2281-2295

Perlwitz J, Graf HF (2001) The variability of horizontal circulation in the troposphere and stratosphere-a comparison. Theor Appl Climatol 69:149-161

Pozo-Vázquez D, Esteban-Parra MJ, Rodrigo FS, Castro-Díez Y (2001) A study of NAO variability and its possible nonlinear influences on European surface temperature. Clim Dyn 17:701-715

Raisanen J, Hansson U, Ullerstig A, Doscher R and 5 others (2004) European climate in the late twenty-first century: regional simulations with two driving global models and two forcing scenarios. Clim Dyn 22:13-31

Rauthe M, Hense A, Paeth H (2004) A model intercomparison study of climate change-signals in extratropical circulation. Int J Climatol 24:643-662

Reid PA, Jones PD, Brown O, Goodess CM, Davies TD (2001) Assessments of the reliability of NCEP circulation data and relationships with surface climate by direct comparisons with station based data. Clim Res 17:247-261

Submitted: April 16, 2005; Accepted: February 25, 2006
Rogers JC (1990) Patterns of low-frequency monthly sealevel pressure variability, 1899-1986 and associated wave cyclone frequencies. J Clim 3:1364-1379

Rogers JC (1997) North Atlantic storm track variability and its association to the North Atlantic Oscillation and climate variability of Northern Europe. J Clim 10:1635-1647

Santos J (2005) Climate variability in Europe and its connection to the tropospheric and stratospheric circulations: a case study for Portugal. PhD thesis, University of Lisbon

Schar C, Vidale PL, Luthi D, Frei C, Haberli C, Liniger MA, Appenzeller $C$ (2004) The role of increasing temperature variability in European summer heatwaves. Nature 427: 332-336

Shabbar A, Huang JP, Higuchi K (2001) The relationship between the wintertime North Atlantic Oscillation and blocking episodes in the North Atlantic. Int J Climatol 21:355

Sneyers R (1975) Sur L'analyse statistique des séries d'observation. World Meteorol Org Tech Note No. 143

Tank AMGK, Konnen GP (2003) Trends in indices of daily temperature and precipitation extremes in Europe, 1946-99. J Clim 16:3665-3680

Tank AMGK, Wijngaard JB, Konnen GP, Bohm R and 35 others (2002) Daily dataset of 20th century surface air temperature and precipitation series for the European Climate Assessment. Int J Climatol 22:1441-1453

Thompson DWJ, Wallace JM (1998) The artic oscillation signature in the wintertime geopotential height and temperature fields. Geophys Res Lett 25:1297-1300

Thompson DWJ, Wallace JM (2000a) Annular modes in the extratropical circulation. Part I: month-to-month variability. J Clim 13:1000-1016

Thompson DWJ, Wallace JM (2000b) Annular modes in the extratropical circulation. Part II: trends. J Clim 13: 1018-1036

Thorne PW, Jones PD, Tett SFB, Allen MR and 5 others (2003) Probable causes of late twentieth century tropospheric temperature trends. Clim Dyn 21:573-591

Trigo RM, Osborn TJ, Corte-Real JM (2002) The North Atlantic Oscillation influence on Europe: climate impacts and associated physical mechanisms. Clim Res 20:9-17

von Storch, Zwiers F (1999) Statistical analysis in climate research. Cambridge University Press, Cambridge

Wijngaard JB, Tank AMGK, Können GP (2003) Homogeneity of the 20th century European daily temperature and precipitation series. Int J Climatol 23:679-692

WMO (World Meteorological Organisation) (1996) Climatological normals (CLINO) for the period 1961-1990. Doc WMO/OMM-No. 847. World Meteorol Org, Geneva

Proofs received from author(s): May 16, 2006 